\title{
BAGAIMANA MENJADIKAN PENDIDIKAN MENJADI PELUANG USAHA
}

\section{Ni’matul Izzah}

\section{Universitas Nahdlatul Ulama Sidoarjo Email: izzah28091996@gmail.com}

Dalam standar nasional pendidikan yang menjadi acuan pengembangan kurikulum KTSP, pendidikan kewirausahaan termasuk materi yang harus diajarkan dan direalisasikan oleh siswa dalam kehiupan sehari-hari. Namun, pendidikan kewirausahaan di sekolah baru pada pengenalan norma dan nilai-nilai, belum pada tindakan nyata dalam kehidupan. Setiap manusia yang memiliki ilmu selayaknya harus mengamalkan ilmu tersebut (Asitah et al., 2017).

\section{Pendidikan adalah suatu kegiatan} pembentukan kesadaran dan kepribadian anak didik di samping transfer ilmu dan keahlian (Qori'ah et al., 2017). Menurut KBBI, pendidikan adalah poses perubahan sikap seseorang dalam upaya mendewasakan manusia. Bisa dikatakan pula pendidikan merupakan proses belajar mengajar 
yang didalamnya terdapat beberapa unsur pendukung. "Pendidikan nasional berfungsi membentuk watak dan peradaban bangsa guna mencerdaskan kehidupan bangsa dan untuk mengembangkan potensi siswa supaya menjadi manusia yang beriman kepada Tuhan Yang Maha Esa, berpengetahuan luas, berbudi pekerti yang mulia, mandiri, kreatif, demokratis, dan bertanggung jawab " Pasal 3 UU Sisdiknas. Pendidikan Indonesia membutuhkan peningkatan akses, mutu dan relevansi pendidikan untuk memberi manfaat membangun bagi pendidikan dan rakyat Indonesia (Irawan et al., 2018). Siswa perlu memahami apa yang diketahui dan apa yang diminta untuk memiliki kemampuan menjawab (Suci et al., 2018).

Tips mengelola institusi pendidikan adalah niat mendidik dan berjuang karena Allah ta'ala. Niscaya rintangan sebesar apapun akan terasa ringan dihadapan kita. Melihat anak mengenal Allah Ta'ala dan sukses akhlak dan pengetahuannya merupakan kebahagiaan pendidik (Yuniarti et al., 2017). Senantiasa harus selalu berpegang teguh pada sifat yang dimiliki oleh Rasul yaitu jujur, amanah, fathana, siddiq selain itu juga harus bermodal ikhas, karena Allah ingin agamanya itu di amalkan, poin yang kedua yaitu do'a para alim dan ulama terdahulu lah yang sangat penting dan point 
yang ke tiga yaitu transparan kepada semua orang agar sesuatu yang di kerjakan mendapat kepercayaan dari orang lain (Munjidah, et al., 2017).

Menurut Kasmir (2006) dalam jurnal, kewirausahaan merupakan kemampuan melakukan kegiatan usaha. Sedangkan menurut Zimmer dalam suryana (2006:14), kewirausahaan adalah penerapan kreativitas untuk memanfaatkan peluang yang ada.

\section{Pendidikan kewirausahaan}

Dunia dan masyarakat membutuhkan kewirausahaan (Setyawati, Purnomo, Irawan, Tamyiz, \& Sutiksno, 2018). Edupreneur atau educational entrepreneur berasal dari dua kata yaitu education bermakna pendidikan dan entrepreneur bermakna pengusaha atau wirausahawan. Ada juga yang menyamakan istilah edupreneur dengan istilah teacherpreneur (Purnomo, 2017). Jadi, pendidikan kewirausahaan adalah proses atau cara untuk memperoleh pengetahuan tentang berwirausaha guna mempersiapkan siswa menghadapi perkembangan IPTEK pada masa sekarang dan yang akan datang. Menurut Churchill dalam Rambat Lupyoadi (2007), pendidikan sangat berperan penting bagi 
keberhasilan seorang wirausahawan dalam menjalankan usahanya.

Kegagalan yang pertama seorang wirausahawan adalah ketika lebih mengutamakan pengalaman daripada pendidikan. Akan tetapi, tidak juga menganggap remeh pengalaman lapangan seorang wirausaha. Kegagalan kedua yaitu apabila wirausahawan hanya bermodalkan pendidikan saja, tetapi miskin pengalaman. Maka dari itu perpaduan antara pengalaman dan juga pendidikan merupakan faktor utama penentu keberhasilan dalam wirausaha.

\section{Nilai-nilai dasar kewirausahaan}

Adapun nilai-nilai dasar yang dapat dijadikan pegangan bagi seorang wirausahawan antara lain:

Tabel 1: Nilai-nilai dasar dan deskripsi kewirausahaan 


\begin{tabular}{|l|l|}
\hline Nilai-nilai dasar & \multicolumn{1}{|c|}{ Deskripsi } \\
\hline Kreatif & $\begin{array}{l}\text { Mampu menghasilkan sesuatu yang baru atau } \\
\text { mengembangkan sesuatu yang telah ada. }\end{array}$ \\
\hline Mandiri & Sikap tidak mudah bergantung pada orang lain. \\
\hline Kepemimpinan & $\begin{array}{l}\text { Dapat mengatur diri sendiri dan orang lain serta mudah } \\
\text { bergaul. }\end{array}$ \\
\hline Kerja keras & $\begin{array}{l}\text { Sungguh-sungguh dalam menyelesaikan tugas dan } \\
\text { mengatasi hambatan. }\end{array}$ \\
\hline Berani & $\begin{array}{l}\text { Mampu melakukan pekerjaan yang menantang serta berani } \\
\text { mengambil resiko. }\end{array}$ \\
\hline $\begin{array}{l}\text { Berorientasi pada } \\
\text { tindakan }\end{array}$ & $\begin{array}{l}\text { Inisiatif dalam bertindak tidak menunggu sebelum kejadian } \\
\text { yang tidak diinginkan terjadi. }\end{array}$ \\
\hline Etika dan norma & Memiliki etika dan norma yang baik. \\
\hline
\end{tabular}

Sumber : Kemendiknas (2010:10)

Nilai-nilai dasar tersebut dapat dikembangkan dalam dunia pendidikan. Generasi muda butuh dibekali nilai-nilai kewirausahaan tersebut agar dapat mengatasi persaingan yang ketat. Pada dasarnya pendidikan bisa dijadikan jembatan penghubung manusia untuk menuju kehidupan lebih baik. Pendidikan kewirausahaan diharapkan dapat mengembangkan jiwa semangat berwirausaha, berkarya dan menumbuhkan perekonomian masyarakat (Jamal Ma'mur Asmani: 2011, dalam jurnal). 


\section{Kesimpulan}

Pendidikan kewirausahaan merupakan media efektif untuk mengembangkan nilai-nilai dasar kewirausahaan pada generasi penerus bangsa sehingga semangatnya lebih kompetitif dalam menghadapi persaingan. Peran pendidikan kewirausahaan sangat dibutuhkan untuk menyiapkan jiwa semangat generasi muda supaya menjadi partisipatoris dalam wirausaha menuju perubahan yang positif.

\section{References}

Asitah, N., Usmawati, D. Z., Nahdiyah, K., Amrina, S., Noviana, E. N., Arifindiarti, E. E., Paramitha, L., Saraswati, G. R. D., Mustafidah, I., Nissa, N. R., Puadah, S., Aidah, N., Purnomo, A. (2017). MI Hasyim Asy'ari IImu Harus Terus Mengarus. In Wirausaha Pendidikan Indonesia (Jilid 2). Sidoarjo: Unusida Press.

Budy, doddy A., (2017, Desember). Pengaruh pendidikan kewirausahaan terhadap keterampilan berwirausaha mahasiswa universitas 17 agustus 1945 jakarta. Journal for business and entrepreneur, vol. 1, 22.

Irawan, D. E., Purnomo, A., Sutiksno, D. U., Abraham, J., Alamsyah, A., Saputra, D. H., Javandira, C., \& Rosyidah, E. (2018). Kajian Pendidikan Tinggi IDRI 
untuk DPR RI dan Ristek Dikti 2018. Bandung: ITB Press.

KBBI. (2018). Pendidikan. Diakses dari https://www.google.co.id/amp/s/kbbi.web.id/pendid ikan.html

Kholifah, N., Nurtanto, M. (2016). Pengembangan pendidikan kewirausahaan dalam menanamkan nilai-nilai entrepreneurship untuk menghadapi masyarakat ekonomi ASEAN. Prosiding seminar nasional inovasi pendidikan, 418.

Munjidah, A, Zannah, I.P.N., Purnomo, A., Rosyidah, E. (2017). Ml Thoriqussalam Berpegang Kepada Rosul. In Wirausaha Pendidikan Indonesia (Jilid 4). Sidoarjo: Unusida Press.

Purnomo, A. (2017, December 5). Pengertian Edupreneur.

http://doi.org/10.17605/OSF.IO/J3BCR

Qori'ah, S., Sholikhah, S.A., Fitriyah, N., Jannah, D.F., Sholichah, S.A., Istiqomah, A., Wijayanti, A.N., Mubarokah, L., Rosyidah, E., Mauliddiyah, A.T., Fauziah, L., Ahmadi, C.N.A., Muid, M., Purnomo, A. (2017). MI Hasyim Asy'ari Ilmu Harus Terus Mengarus. In Wirausaha Pendidikan Indonesia (Jilid 3). Sidoarjo: Unusida Press.

Setyawati, I., Purnomo, A., Irawan, D. E., Tamyiz, M., \& Sutiksno, D. U. (2018). A Visual Trend of Literature on Ecopreneurship Research Overviewed within The Last two Decades. Journal of Entrepreneurship Education, 21(4), 1-7. Retrieved from https://www.abacademies.org/articles/a-visual- 
trend-of-literature-on-ecopreneurship-researchoverviewed-within-the-last-two-decades-7468.html

Suci, S. H. A., Rosyidah, E., Asitah, N., Aini, N., Murni, A. W., Anam, F., Purnomo, A., Sallu, S., Mulyaningsih, I., \& Kuraesin, A. D. (2018). Learning from Picture and Picture Action Research: Enhancement of Counting Ability on Division of Numbers for Primary School Students. Journal of Physics: Conference Series, 1114, 012044. https://doi.org/10.1088/1742$\underline{6596 / 1114 / 1 / 012044}$

Yuniarti, D., Kautsari, M.F., Sholichah, F., Purnomo, A., \& Rosyidah, E. (2017). SMP SMA Al-Amin Ponpes Bahrul Hidayah Serahkan pada Allah Ta'ala. In Wirausaha Pendidikan Indonesia (Jilid 1). Sidoarjo: Unusida Press. 